\title{
Maternal drinking and smoking. Can it explain the exceptional academic performance of LBOTE children? A preliminary analysis
}

\author{
Louisa Gibson * (D) and Melanie Porter
}

\begin{abstract}
Objective: Although children from language backgrounds other than English (LBOTE) may be disadvantaged in English-reliant exams, they outperform children from an English language background (ELB) on many Australian National Assessment Program-Literacy and Numeracy (NAPLAN) assessments. Maternal alcohol and tobacco use during pregnancy and/or breastfeeding have been associated with poorer cognitive and academic performance. Using data from the Growing Up in Australia Study, this paper aimed to identify demographic, lifestyle, and prenatal and perinatal risk differences related to maternal tobacco and alcohol use between LBOTE and ELB groups, as a first step in trying to understand the academic performance differences.

Results: Only data from breastfed babies was included in the current analyses. Although LBOTE children were disadvantaged in several demographic areas, their NAPLAN performance was the same or superior to ELB children across all Grade 3 and 5 NAPLAN assessments. The LBOTE group were, however, breastfed for longer, and their mothers smoked fewer cigarettes and drank less alcohol on fewer occasions throughout their pregnancy. The LBOTE mothers also had lower or less risky patterns of alcohol consumption while breastfeeding. The longer breastfeeding duration of LBOTE children combined with lower maternal use of alcohol and cigarettes during pregnancy and/or breastfeeding may partially contribute to their exceptional NAPLAN performance.
\end{abstract}

Keywords: Academic achievement, Non-English speaking background, Drinking, Smoking, Breastfeeding, Pregnancy

\section{Introduction}

Children from language backgrounds other than English (LBOTE) perform better than children from an English language background (ELB) in many of the Australian National Assessment Program-Literacy and Numeracy (NAPLAN) assessments [1, 2]. While it has been suggested that this may be due to inadequacies in the NAPLAN LBOTE measure [3, 4], it is possible that health, family, lifestyle, environmental or socio-economic status (SES) factors may be at least partly responsible.

*Correspondence: louisa.gibson@hdr.mq.edu.au

Faculty of Medicine, Health and Human Sciences, Department

of Psychology, Macquarie University, Balaclava Road, North Ryde, Sydney, NSW 2109, Australia
The NAPLAN assessments are a series of English-reliant annual tests in reading, writing, language conventions (spelling, grammar and punctuation) and numeracy. These tests are given to all Australian children in grades $3,5,7$ and 9 [1].

Given that greater English proficiency has been associated with superior academic performance [5], LBOTE children may be disadvantaged. Despite this expectation, it has been repeatedly observed that LBOTE children perform better on NAPLAN tests of writing, spelling, grammar and numeracy [2]. Although it is possible that disadvantaged LBOTE children may tend to stay home on the day of NAPLAN assessments, Creagh $[3,4]$ suggested that the superior performance of LBOTE students 
is due to the way LBOTE status is assigned being an inadequate measure of English proficiency.

If usual ways of measuring LBOTE status are biased in favour of LBOTE children, or fail to measure English proficiency, LBOTE children would be expected to outperform ELB children across different education systems that utilise similar LBOTE measures. While LBOTE children in the United Kingdom did outperform ELB children for the first time in 2017 [6], LBOTE students in the United States [7] and Canada [8] perform more poorly on academic assessments. This suggests that other factors may contribute to the superior performance of LBOTE students.

Children's academic achievement may be impacted by many cognitive, physiological, lifestyle, environmental and SES variables. Socio-economic factors such as lower parental education and income have been shown to negatively impact academic achievement in children [9], while homework completion has been associated with improved outcomes [10]. Higher parental expectations and receiving assistance with homework have also been associated with greater academic achievement [11]. Additionally, older age [12], and higher birth weight [13], are all related to greater cognitive ability, which in itself is associated with better academic outcomes [14]. Sex differences in individual cognitive abilities have also been postulated [15]. Additionally, while there is conflicting evidence [16], longer breastfeeding duration has further been associated with increased cognitive ability [17].

Prenatal maternal alcohol and tobacco intake have also been found to negatively impact children's academic performance $[18,19]$. While no changes in developmental health outcomes have been observed [20], dose-dependent reductions in cognitive and academic outcomes have been found in children of mothers who consumed alcohol while breastfeeding $[21,22]$. This suggests that maternal alcohol consumption or tobacco smoking while breastfeeding may be additional factors that contribute to differences in academic achievement between LBOTE and ELB children.

Using data from Growing Up in Australia: The Longitudinal Study of Australian Children (LSAC) [23], the current study was a preliminary analysis describing the differences in lifestyle, demographic, SES and maternal drinking and smoking habits between LBOTE and ELB groups in a sample of Australian breastfed babies. The primary goal was to identify demographic, lifestyle, and prenatal and perinatal risk differences related to maternal tobacco and alcohol use between the two groups as a first step in trying to understand the academic performance differences. It was anticipated that differences would be observed between the two groups that may help to explain the superior performance of LBOTE students, and provide a basis for future research.

\section{Main text \\ Method \\ Study design, data source and study cohort}

The study cohort has been described previously [20-22]. Briefly, data was sourced from LSAC. The study cohort comprised 5107 infants and caregivers from LSAC who were recruited in 2004 (average age of 9 months) and followed over time every two years in waves [24]. Six data waves were available for analyses. Only babies who were breastfeeding at study entry (Wave 1) with data available from their biological mothers were included in the analyses.

\section{Study variables}

The sample was divided into LBOTE and ELB children. All other variables were compared between these two groups. The language background of children was categorised as LBOTE if the primary language spoken at home at study entry was not English, and ELB if the primary language was English. Other study variables described previously [21,22] included:

\section{Academic outcome variables}

- Grades 3 and 5 NAPLAN reading scores

- Grades 3 and 5 NAPLAN writing scores

- Grades 3 and 5 NAPLAN spelling scores

- Grades 3 and 5 NAPLAN grammar and punctuation scores

- Grades 3 and 5 NAPLAN numeracy scores

\section{Demographic variables}

- Sex of child

- Birth weight (grams)

- Combined family annual income \$AUD (higher score indicates lower income)

- Maternal education

- Breastfeeding duration (days)

- Age at Grade 3 NAPLAN test

- Age at Grade 5 NAPLAN test

\section{Tobacco and alcohol use variables}

- Maternal average daily cigarettes smoked while pregnant

- Maternal average daily cigarettes smoked while breastfeeding 
- Maternal alcohol consumed while breastfeeding (mother's total modified version of The Alcohol Use Disorders Identification Test Alcohol Consumption Questions; AUDIT-C [25, 26] score at wave 1)

- Days per week mother drank alcohol during first trimester of pregnancy

- Days per week mother drank alcohol during second trimester of pregnancy

- Days per week mother drank alcohol during third trimester of pregnancy

- Average number of alcoholic drinks mother consumed on each drinking occasion during pregnancy

Additional homework and tutoring variables are described in Table 1.

\section{Statistical analyses}

Data was analysed using IBM SPSS version $24(\alpha=0.05$, 2 -tailed). Due to data skew, variables were analysed using Kruskal-Wallis $\mathrm{H}$ tests, with the exception of dichotomous variables that were analysed using a one-way analysis of variance (ANOVA). To ensure that the academic performance between LBOTE and ELB children was not an artefact of lower SES LBOTE children being kept home on the day of assessment, two-way analyses of variance were used to determine maternal education and combined family income interaction effects between NAPLAN completers and non-completers across LBOTE and ELB groups. Corrections for multiple comparisons were not made, since the purpose of the study was to provide a brief and preliminary descriptive analysis of the sample between groups.

\section{Results}

It was found that LBOTE children performed better than ELB children on grade 3 NAPLAN writing and spelling tests, as well as grade 5 NAPLAN spelling tests. It was also observed that LBOTE children were younger at the time of grade 3 NAPLAN tests, were from lower income families and were of lower birthweight than ELB children. Mothers of LBOTE children smoked fewer cigarettes during pregnancy and while breastfeeding, and had lower alcohol drinking scores while breastfeeding. They also drank alcohol on fewer days per week during each trimester of pregnancy and consumed less alcohol on each occasion. No other differences between LBOTE and ELB children were observed (Table 2a-d).

Results indicated that Grade 3 and 5 NAPLAN noncompleters were from families with lower levels of maternal education and lower family incomes $(F=15.77-24.59$, $\mathrm{p}^{<}$0.001). For Grade 3 NAPLAN completers and noncompleters, the magnitude of these differences did not vary between LBOTE and ELB groups $(\mathrm{F}=1.78-3.87$, $\mathrm{p}=0.05-0.18)$. In contrast to this, the magnitude of the difference in maternal education $(F=6.07-7.12$, $\mathrm{p}=0.01)$, but not family income $(\mathrm{F}=0.25-0.76, \mathrm{p}=0.38$ $0.55)$, was greater in the LBOTE group for grade 5 NAPLAN completers and non-completers.

\section{Discussion}

The academic performance of breastfeeding LBOTE children was the same or superior to ELB children across all NAPLAN tests. Separate analyses also found that LBOTE children were of lower birthweight, from families of lower income, of the same or younger age at the time of NAPLAN tests, and received the same or less amount of homework, homework assistance, and tutoring. There were no differences between LBOTE and ELB children regarding sex, level of maternal education or the number of cigarettes their mothers smoked while breastfeeding. Contrastingly, LBOTE children were breastfed for longer than ELB children, and their mothers smoked fewer cigarettes during pregnancy. Mothers of LOBTE children also drank less alcohol on fewer occasions throughout their pregnancy, and had lower or less risky patterns of alcohol consumption while breastfeeding.

Non-completing NAPLAN children were found to be from families with lower levels of maternal education and family income. The magnitude of this difference did not vary between LBOTE and ELB groups in Grade 3, or regarding Grade 5 income. There was, however, a greater difference in the magnitude of the difference among LBOTE children in relation to maternal education in Grade 5.

These findings are somewhat contradictory. The superior performance of LBOTE children across some of the NAPLAN assessments has been previously observed [2], and lack of sex differences or maternal smoking during breastfeeding is unsurprising $[15,21,22]$. Contrastingly, however, the lower birthweight and family income $[9,13]$, younger age at the time of grade 3 NAPLAN assessments [12], and lack of additional homework, homework assistance or tutoring $[10,11]$, would be expected to disadvantage LBOTE children. Even in NAPLAN assessments where LBOTE children matched the performance of ELB children, findings are still unexpected given their LBOTE status [5].

Creagh [3, 4] suggested that the measurement of the LBOTE category itself is flawed, which may account for the superior or matched performance of LBOTE children on NAPLAN assessments. Additionally, and despite observed disadvantages, it is also possible that LBOTE children have some advantages that may also contribute to their performance. For example, the LBOTE group were breastfed for longer. Longer breastfeeding duration has been associated with better cognitive outcomes [17]. 
Table 1 Description and response options for variables included in analyses

\begin{tabular}{|c|c|c|}
\hline Variable & Description & Response options and values \\
\hline Homework frequency (Wave 4) & How often does study child do homework? & $\begin{array}{l}\text { 1: Daily } \\
\text { 2: A few times a week } \\
\text { 3: Once a week } \\
\text { 4: A few times a month } \\
\text { 5: Once a month } \\
\text { 6: Less than once a month } \\
\text { 7: Never }\end{array}$ \\
\hline Homework help (Wave 4) & $\begin{array}{l}\text { During this school year, how often have you or another family member (or } \\
\text { adult in the household) helped study child with his/her homework? }\end{array}$ & $\begin{array}{l}\text { 1: Daily } \\
\text { 2: A few times a week } \\
\text { 3: Once a week } \\
\text { 4: A few times a month } \\
\text { 5: Less often }\end{array}$ \\
\hline Tutoring (Wave 4) & $\begin{array}{l}\text { In the last } 12 \text { months has the study child received any additional help or } \\
\text { tutoring from anyone outside the household? }\end{array}$ & $\begin{array}{l}\text { 1: Yes } \\
\text { 2: No } \\
\text { (-2: Don't know-coded as missing data) }\end{array}$ \\
\hline Tutoring frequency (Wave 4) & How often? & $\begin{array}{l}\text { 1: More than once a week } \\
\text { 2: Once a week } \\
\text { 3: Less than once a week } \\
\text { (-2: Don't know-coded as missing data) }\end{array}$ \\
\hline Homework hours (Wave 5) & $\begin{array}{l}\text { In an average week, how many hours does study child spend on homework } \\
\text { outside of school? }\end{array}$ & Number of hours \\
\hline Homework help (Wave 5) & $\begin{array}{l}\text { During this school year, how often did someone in this household help } \\
\text { study child with homework? }\end{array}$ & $\begin{array}{l}\text { 1: } 5 \text { or more days a week } \\
\text { 2: } 3 \text { or } 4 \text { days a week } \\
\text { 3: } 1 \text { or } 2 \text { days a week } \\
\text { 4: Less than once a week } \\
\text { 5: Never }\end{array}$ \\
\hline Tutoring (Wave 5) & $\begin{array}{l}\text { In the last } 12 \text { months has study child received any additional help or tutor- } \\
\text { ing from anyone outside the household? }\end{array}$ & $\begin{array}{l}\text { 1: Yes } \\
\text { 2: No } \\
\text { (-2: Don't know-coded as missing data) }\end{array}$ \\
\hline Tutoring frequency (Wave 5) & How often? & $\begin{array}{l}\text { 1: More than once a week } \\
\text { 2: Once a week } \\
\text { 3: Less than once a week } \\
\text { (-2: Don't know-coded as missing data) }\end{array}$ \\
\hline Homework hours (Wave 6) & $\begin{array}{l}\text { In an average week, how many hours does study child spend on homework } \\
\text { outside of school? }\end{array}$ & Number of hours \\
\hline Homework help (Wave 6) & $\begin{array}{l}\text { During this school year, how often did someone in this household help } \\
\text { study child with his/her homework? }\end{array}$ & $\begin{array}{l}\text { 1: } 5 \text { or more days a week } \\
\text { 2: } 3 \text { or } 4 \text { days a week } \\
\text { 3: } 1 \text { or } 2 \text { days a week } \\
\text { 4: Less than once a week } \\
\text { 5: Never }\end{array}$ \\
\hline Tutoring (Wave 6) & $\begin{array}{l}\text { In the last } 12 \text { months has study child received any additional help or tutor- } \\
\text { ing from anyone outside the household? }\end{array}$ & $\begin{array}{l}\text { 1: Yes } \\
\text { 2: No } \\
\text { (-2: Don't know-coded as missing data) }\end{array}$ \\
\hline Tutoring frequency (Wave 6) & How often? & $\begin{array}{l}\text { 1: More than once a week } \\
\text { 2: Once a week } \\
\text { 3: Less than once a week } \\
\text { (-2: Don't know-coded as missing data) }\end{array}$ \\
\hline
\end{tabular}


Table 2 Results of ANOVA and Kruskal-Wallis H tests between LBOTE and ELB groups

\begin{tabular}{|c|c|c|c|c|c|c|}
\hline \multirow[t]{2}{*}{ Variable } & \multicolumn{2}{|c|}{ LBOTE } & \multicolumn{2}{|l|}{ ELB } & \multirow[t]{2}{*}{ Statistic } & \multirow[t]{2}{*}{$p$-value } \\
\hline & N & M (SD) & $\mathrm{N}$ & $\mathrm{M}(\mathrm{SD})$ & & \\
\hline \multicolumn{7}{|l|}{ (a) Academic outcome variables } \\
\hline Grade 3 NAPLAN reading scores & 137 & $449.28(89.86)$ & 1379 & $446.71(93.45)$ & $0.23^{\mathrm{b}}$ & 0.63 \\
\hline Grade 3 NAPLAN writing scores & 137 & $442.38(59.53)$ & 1372 & $426.30(61.22)$ & $10.50^{\mathrm{b}}$ & $<0.01$ \\
\hline Years 3 NAPLAN spelling scores & 137 & $450.78(91.44)$ & 1372 & $420.09(77.15)$ & $19.56^{b}$ & $<0.001$ \\
\hline Grade 3 NAPLAN grammar and punctuation scores & 137 & $461.09(97.80)$ & 1372 & $446.30(90.16)$ & $1.61^{\mathrm{b}}$ & 0.21 \\
\hline Grade 3 NAPLAN numeracy scores & 135 & $424.48(84.01)$ & 1376 & $415.24(72.24)$ & $0.93^{b}$ & 0.34 \\
\hline Grade 5 NAPLAN reading scores & 113 & $523.74(81.73)$ & 1257 & $529.52(81.65)$ & $0.31^{\mathrm{b}}$ & 0.58 \\
\hline Grade 5 NAPLAN writing scores & 112 & $492.97(66.66)$ & 1249 & $482.38(65.38)$ & $3.61^{\mathrm{b}}$ & 0.06 \\
\hline Grade 5 NAPLAN spelling scores & 112 & $535.73(76.60)$ & 1257 & $505.73(71.96)$ & $14.28^{b}$ & $<0.001$ \\
\hline Grade 5 NAPLAN grammar and punctuation scores & 112 & $540.00(91.40)$ & 1257 & $528.35(83.39)$ & $1.51^{b}$ & 0.22 \\
\hline \multirow[t]{2}{*}{ Variable } & \multicolumn{2}{|c|}{ LBOTE } & \multicolumn{2}{|l|}{ ELB } & Statistic & p-value \\
\hline & N & $\mathrm{M}(\mathrm{SD})$ & $\mathrm{N}$ & $M(S D)$ & & \\
\hline \multicolumn{7}{|l|}{ (b) Demographic variables } \\
\hline Sex (male/female) & 215 & $1.53(0.50)$ & 1790 & $1.50(0.50)$ & $0.81^{\mathrm{a}}$ & 0.37 \\
\hline Birth weight (grams) & 213 & $3399.42(523.14)$ & 1780 & $3478.84(539.92)$ & $5.65^{b}$ & 0.02 \\
\hline Combined family annual income \$AUD * & 196 & $6.67(2.93)^{*}$ & 1691 & $5.53(2.56)^{*}$ & $26.22^{b}$ & $<0.001$ \\
\hline Maternal education & 213 & $6.22(1.78)$ & 1788 & $6.30(1.49)$ & $0.01^{\mathrm{b}}$ & 0.93 \\
\hline Breastfeeding duration (days) & 200 & $255.98(202.93)$ & 1546 & $228.87(203.93)$ & $4.60^{b}$ & 0.03 \\
\hline Age at Grade 3 NAPLAN test (months) & 141 & $101.77(4.16)$ & 1429 & $102.68(4.27)$ & $4.17^{\mathrm{b}}$ & 0.04 \\
\hline Age at Grade 5 NAPLAN test (months) & 119 & $125.61(3.90)$ & 1293 & $126.09(3.57)$ & $1.34^{b}$ & 0.25 \\
\hline \multirow[t]{2}{*}{ Variable } & \multicolumn{2}{|l|}{ LBOTE } & \multicolumn{2}{|l|}{ ELB } & Statistic & p-value \\
\hline & N & $\mathrm{M}(\mathrm{SD})$ & N & $\mathrm{M}(\mathrm{SD})$ & & \\
\hline \multicolumn{7}{|l|}{ (c) Tobacco and alcohol use variables } \\
\hline Maternal average daily cigarettes smoked while pregnant & 143 & $0.14(1.07)$ & 1523 & $0.66(2.65)$ & $9.29^{b}$ & $<0.01$ \\
\hline Maternal average daily cigarettes smoked while breastfeeding & 165 & $0.45(2.02)$ & 1590 & $1.06(3.79)$ & $2.87^{b}$ & 0.09 \\
\hline Days per week mother drank alcohol during 1st trimester of pregnancy & 150 & $0.06(0.35)$ & 1584 & $0.18(0.74)$ & $5.13^{b}$ & 0.02 \\
\hline Days per week mother drank alcohol during 2nd trimester of pregnancy & 150 & $0.04(0.26)$ & 1582 & $0.22(0.76)$ & $10.25^{\mathrm{b}}$ & $<0.01$ \\
\hline Days per week mother drank alcohol during 3rd trimester of pregnancy & 150 & $0.05(0.28)$ & 1581 & $0.25(0.87)$ & $8.02^{b}$ & 0.01 \\
\hline $\begin{array}{l}\text { Average number of alcoholic drinks mother consumed on each drinking } \\
\text { occasion during pregnancy }\end{array}$ & 150 & $0.19(0.41)$ & 1579 & $0.48(0.54)$ & $41.47^{\mathrm{b}}$ & $<0.001$ \\
\hline Maternal alcohol consumed while breastfeeding & 151 & $3.09(2.48)$ & 1338 & $5.83(2.29)$ & $126.69^{b}$ & $<0.001$ \\
\hline \multirow[t]{2}{*}{ Variable } & \multicolumn{2}{|l|}{ LBOTE } & \multicolumn{2}{|l|}{ ELB } & Statistic & p-value \\
\hline & N & $M(S D)$ & N & $M(S D)$ & & \\
\hline \multicolumn{7}{|l|}{ (d) Homework and tutoring variables } \\
\hline Homework frequency (Wave 4) & 178 & $1.38(0.74)$ & 1392 & $1.39(0.64)$ & $0.36^{b}$ & 0.55 \\
\hline Homework help (Wave 4) & 178 & $1.45(0.74)$ & 1392 & $1.44(0.71)$ & $0.04^{b}$ & 0.84 \\
\hline Tutoring (Wave 4) & 178 & $1.88(0.32)$ & 1389 & $1.89(0.31)$ & $0.14^{\mathrm{a}}$ & 0.71 \\
\hline Tutoring frequency (Wave 4) & 20 & $1.70(0.57)$ & 151 & $1.81(0.68)$ & $0.33^{b}$ & 0.57 \\
\hline Homework hours (Wave 5) & 164 & $2.70(2.11)$ & 1333 & $2.48(1.80)$ & $0.82^{b}$ & 0.37 \\
\hline Homework help (Wave 5) & 164 & $2.25(1.04)$ & 1333 & $2.12(0.99)$ & $2.40^{b}$ & 0.12 \\
\hline Tutoring (Wave 5) & 168 & $1.89(0.32)$ & 1387 & $1.84(0.37)$ & $2.46^{\mathrm{a}}$ & 0.12 \\
\hline Tutoring frequency (Wave 5) & 19 & $1.63(0.50)$ & 219 & $1.85(0.63)$ & $2.05^{b}$ & 0.15 \\
\hline Homework hours (Wave 6) & 146 & $2.77(1.99)$ & 1164 & $2.74(1.90)$ & $<0.001^{b}$ & 0.99 \\
\hline Homework help (Wave 6) & 146 & $2.47(1.03)$ & 1164 & $2.64(1.01)$ & $4.23^{b}$ & 0.04 \\
\hline Tutoring (Wave 6) & 153 & $1.79(0.41)$ & 1239 & $1.84(0.37)$ & $1.92^{\mathrm{a}}$ & 0.17 \\
\hline Tutoring frequency (Wave 6) & 32 & $1.88(0.55)$ & 203 & $1.87(0.57)$ & $0.01^{b}$ & 0.93 \\
\hline
\end{tabular}


Table 2 (continued)

LBOTE Language Background other than English, ELB English Language Background

${ }^{*}$ Higher scores indicate lower income; ${ }^{a}$ value; ${ }^{b} X^{2}$ value

Likewise, the lower prenatal maternal tobacco and alcohol use $[18,19]$, and lower or less risky maternal use of alcohol while breastfeeding in LBOTE children [21, 22], has been previously associated with improved cognitive and academic outcomes.

While it would be premature to directly attribute the NAPLAN performance of LBOTE children to these breastfeeding and tobacco and alcohol measures, it is nonetheless noteworthy that these were the only variables in which LBOTE children were advantaged over ELB children. As such, it is possible that longer breastfeeding duration, lower prenatal maternal tobacco and alcohol use, and lower or less risky maternal use of alcohol while breastfeeding may partially contribute to the achievement of LBOTE children in NAPLAN assessments. This suggests that maternal factors may impact the academic performance of children at a later age.

Alternatively, LBOTE children who complete NAPLAN may be from more advantaged families than LBOTE children who do not complete NAPLAN. The NAPLAN completers were found to be from higher income families with greater maternal education regardless of language status. Since, however, the magnitude of this difference was only greater in LBOTE children when examining Grade 5 income, and Grade 3 LBOTE children also had significant academic achievement, this theory does not sufficiently explain the findings.

The academic performance of LBOTE children was the same or superior to ELB children across all Grade 3 and 5 NAPLAN assessments. This was despite LBOTE children being of lower birthweight, lower family income, of the same or younger age at the time of NAPLAN assessments, and receiving the same or less amount of homework, homework assistance, and tutoring. Additionally, LBOTE children breastfed for longer than ELB children, and their mothers smoked fewer cigarettes during pregnancy. Mothers of LOBTE children also drank less alcohol on fewer occasions throughout their pregnancy, and had lower or less risky patterns of alcohol consumption while breastfeeding. Since these factors have all been previously associated with improved cognitive or academic performance, they may partially help to explain the academic performance of LBOTE children. Future research should seek to clarify this, and more comprehensively assess the contribution of breastfeeding duration and maternal use of alcohol and tobacco on academic performance.

\section{Limitations}

There were several limitations. These were simple analyses without correction for multiple comparisons. Additionally, using a parametric test to analyse differences between NAPLAN completers and non-completers may introduce error, given mild to moderate skew. Many of the variables relied on self-report measures, and biological confirmation of substance use was not undertaken. It was also not possible to combine alcohol and smoking variables due to measurement differences. Caution must therefore be used when interpreting findings. Future research should seek to conduct more complex analyses and identify the magnitude to which these breastfeeding and alcohol and tobacco variables may be contributing to the academic performance of LBOTE children.

\section{Abbreviations}

LBOTE: Language backgrounds other than English; ELB: English language background; NAPLAN: National Assessment Program-Literacy and Numeracy; SES: Socio-economic status; LSAC: Growing Up in Australia: The Longitudinal Study of Australian Children; AUDIT-C: The Alcohol Use Disorders Identification Test Alcohol Consumption Questions; ANOVA: Analysis of variance.

\section{Acknowledgements}

This paper uses unit record data from Growing Up in Australia, the Longitudinal Study of Australian Children. The study is conducted in partnership between the Department of Social Services (DSS), the Australian Institute of Family Studies (AIFS) and the Australian Bureau of Statistics (ABS). The findings and views reported in this paper are those of the author and should not be attributed to DSS, AIFS or the ABS. Louisa Gibson was also in receipt of a Research Training Program scholarship from the Australian Government Department of Education.

\section{Authors' contributions}

LG conceptualised the research topic, designed the analyses, conducted all analyses, drafted the initial manuscript, and reviewed and revised the manuscript. MP assisted in the design of the analyses and reviewed and revised the manuscript. All authors read and approved the final manuscript.

Funding

No funding was provided for the study,

\section{Availability of data and materials}

The dataset analysed during the current study is available by application to LSAC via the instructions available here: https://growingupinaustralia.gov.au/ data-and-documentation

\section{Declarations}

\section{Ethics approval and consent to participate}

Ethics approval was obtained from Macquarie University Human Research Ethics Committee (ref no. 5201822862659, 7th April 2017). Data was accessed by application to LSAC using Macquarie University's Organisational Deed of Licence. All data provided by LSAC was anonymised.

Consent for publication Not applicable. 


\section{Competing interests}

The authors declare that they have no competing interests.

Received: 16 November 2020 Accepted: 25 March 2021

Published online: 16 April 2021

\section{References}

1. National Assessment Program [https://www.nap.edu.au/home]

2. NAPLAN National Reports [https://www.nap.edu.au/results-and-reports/ national-reports]

3. Creagh S. A critical analysis of problems with the LBOTE category on the NAPLaN test. Australian Educat Res. 2014;41(1):1-23.

4. Creagh S. 'Language Background Other Than English': a problem NAPLaN test category for Australian students of refugee background. Race Ethn Educ. 2016;19(2):252-73.

5. Wongtrirat R. English language proficiency and academic achievement of international students: a meta-analysis (Order No. 3417016). Norfolk: Old Dominion University; 2010.

6. Department for Education. Revised GCSE and equivalent results in England, 2016 to 2017 (SFR01/2018). London: Department for Education, Government of the United Kingdom; 2018.

7. Snyder TD, de Brey C, Dillow SA. Digest of Education Statistics 2017 (NCES 2018-070). Washington, DC:: National Center for Education Statistics, Institute of Education Sciences, U.S. Department of Education; 2019.

8. Brochu P, O'Grady K, Scerbina T, Tao Y: PIRLS/ePIRLS 2016 Canada in Context: Canadian results from the progress in international reading literacy Study. Toronto, Ontario M4V 1N6: council of ministers of education, Canada. 2018

9. Sirin SR. Socioeconomic status and academic achievement: a metaanalytic review of research. Rev Educ Res. 2005;75(3):417-53.

10. Cooper H, Robinson JC, Patall EA. Does homework improve academic achievement? A synthesis of research, 1987-2003. Rev Educ Res. 2006;76(1):1-62

11. Wilder S. Effects of parental involvement on academic achievement: a meta-synthesis. Educ Rev. 2014;66(3):377-97.

12. Verhaeghen $P$, Salthouse TA. Meta-analyses of age-cognition relations in adulthood: estimates of linear and nonlinear age effects and structural models. Psychol Bull. 1997;122(3):231-49.

13. Aarnoudse-Moens CSH, Weisglas-Kuperus N, van Goudoever JB, Oosterlaan J. Meta-analysis of neurobehavioral outcomes in very preterm and/ or very low birth weight children. Pediatrics. 2009;124(2):717-28.
14. Roth B, Becker N, Romeyke S, Schäfer S, Domnick F, Spinath FM. Intelligence and school grades: a meta-analysis. Intelligence. 2015;53:118-37.

15. Hyde JS, McKinley NM: Chapter 2: Gender differences in cognition. Results from meta-analyses. In: Gender Differences in Human Cognition. 1 edn. New York: Oxford University Press; 1997: 30-51.

16. Jain A, Concato J, Leventhal JM. How good is the evidence linking breastfeeding and intelligence? Pediatrics. 2002;109(6):1044-53.

17. Bernard JY, Armand M, Peyre H, Garcia C, Forhan A, De Agostini M, Charles MA, Heude B. Breastfeeding, polyunsaturated fatty acid levels in colostrum and child intelligence quotient at age 5-6 years. J Pediatr. 2017;183(43-50):e43.

18. O'Leary CM, Taylor C, Zubrick SR, Kurinczuk JJ, Bower C. Prenatal alcohol exposure and educational achievement in children aged 8-9 Years. Pediatrics. 2013;132(2):e468-75.

19. Cho K, Frijters JC, Zhang H, Miller LL, Gruen JR. Prenatal exposure to nicotine and impaired reading performance. J Pediatr. 2013;162(4):713-718. e712.

20. Gibson L, Porter M. Drinking or smoking while breastfeeding and later developmental health outcomes in children. BMC Res Notes. 2020. https://doi.org/10.1186/s13104-13020-05072-13108.

21. Gibson L, Porter M. Drinking or smoking while breastfeeding and later cognition in children. Pediatrics. 2018. https://doi.org/10.1542/peds. 2008-1536.

22. Gibson L, Porter M. Drinking or smoking while breastfeeding and later academic outcomes in children. Nutrients. 2020;12(3):829. https://doi. org/10.3390/nu12030829.

23. Growing Up in Australia: The Longitudinal Study of Australian Children [https://growingupinaustralia.gov.au/]

24. Publications [http://www.growingupinaustralia.gov.au/pubs/index.html]

25. Babor TF, Higgins-Biddle JC, Saunders JB, Monteiro MG, World Health Organization: AUDIT: The alcohol use disorders identification test: Guidelines for use in primary health care, vol. WHO/MSD/MSB/01.6a: World Health Organization; 2001.

26. Bush K, Kivlahan DR, McDonell MB, Finn SD, Bradley KA. The AUDIT alcohol consumption questions (AUDIT-C): An effective brief screening test for problem drinking. Arch Intern Med. 1998;158(16):1789-95.

\section{Publisher's Note}

Springer Nature remains neutral with regard to jurisdictional claims in published maps and institutional affiliations.
Ready to submit your research? Choose BMC and benefit from:

- fast, convenient online submission

- thorough peer review by experienced researchers in your field

- rapid publication on acceptance

- support for research data, including large and complex data types

- gold Open Access which fosters wider collaboration and increased citations

- maximum visibility for your research: over 100M website views per year

At BMC, research is always in progress.

Learn more biomedcentral.com/submissions 